\title{
Quality Control Concepts in the Manufacture of Masonry Blocks for Building Project Delivery
}

\author{
C.I. Anyanwu \\ Department of Project Management Technology School of Management Technology Federal University of \\ Technology, Owerri
}

\begin{abstract}
This research work was undertaken to assess the application of quality control concepts in the production of masonry blocks for building projects in Imo State, Nigeria. The study was embarked upon in order to examine the different types of masonry blocks produced in the state, and to assess the level of quality control concepts applied in their production processes, using selected block industries in Owerri Municipality. The study also was aimed at finding out the educational qualifications of the workers at those block industries. The research was an attempt to search for answers to the problem of building and infrastructural collapse that has become rampant in Nigeria recently. Data for the research was collected through the views of the staff and management of the case study block industries and data analysis which was carried out by the use of percentages and frequency tables and chi-square statistical tool, revealed that the problem of low quality masonry blocks used in building projects were due to several latent factors like "time lag" between mixing and placing of mix into mould; mould of placing mix into mould before compaction; type of cement; and inappropriate sand-cement-water mixture ratio. These things were found to have great and decisive effects on the ultimate strength and quality of the building blocks. The research also revealed that poor mixing of cement, sand and water, lack of quality control measures and low quality sand were responsible for low quality blocks in many block producing small and medium scale industries. This situation is contributing to building and infrastructural collapse. The study therefore recommends that quality control concepts should be applied in the production of masonry blocks. The use of acceptance sampling tests for all the raw materials used in masonry block production and application of control-chart for work-in-process should be adopted. The pre-process, inprocess, and post-process inspections and testings must be carried out for the production and standardization of high- quality building blocks before the products are made available to the customer.
\end{abstract}

Key words: Quality control concepts, Masonry blocks, Building project delivery, types of cement, aggregate mixing .

\section{Introduction}

Quality control is the use of techniques and activities to achieve, sustain and improve the quality of a product or service. It involves integrating techniques and activities such as specification of what is needed.

International standard organization, defines quality control as operational techniques and activities that are used to fulfill requirement for quality. ${ }^{2}$

In the block industry, the quality control methods used for inspection and testing for quality control are screening or $100 \%$ inspection, sampling or lot by lot inspection and process inspection. The application of quality control in the block industry should cover the whole production process right from the raw material stage to the finished product. The control areas should start with the control of raw materials, in process control, control of finished products, visual control and physical control which has to do with quality control tests. Proper control measures in the manufacturing process should result in the following:

- Decrease in reject rate and increase in product quality.

- Reduction in price of products hence better value for money.

- Increase in product yield which should make economic mass production possible.

- Reduction in production and distribution/delivery cost.

- Good reputation for the industry and improved.

\section{The Problem}

Consumers of building products and services always want the best quality. Building construction firms are therefore gearing efforts towards providing high quality products in order to withstand the ever-increasing competition in the construction industry. Examples of such firms is Julius Berger Nig. Plc. But unfortunately, masonry blocks produced these days are very fragile, weak and hardly resist minor impact load. Many cases of block breakages have been recorded during molding, parking, handling and transportation and during block laying processes. As a result, customers have started loosing confidence in the products of block industries as 
many rejects are recorded in each transaction. If this development is not checked, it would result into loss of customers, low productivity, under utilization of production facilities, unemployment and other social problems for the block industries.

The incessant incidence of collapsed finished buildings or building work-in-progress is becoming rampart, and this could be attributed to problems that may include defective blocks used in the construction work. For instance, there is a building that collapsed along Owerri-Onitsha road in Imo State recently. This resulted into a wastage of resources, repeat work, delay in project delivery, high quality control costs, possible project abandonment, and above all, loss of lives. Often times, the presence of horizontal and vertical cracks is noticeable in many building structures. Such defects are capable of weakening the entire structure and this is as a result of low quality blocks used in the building project. It becomes necessary therefore to examine the process through which building blocks are manufactured in Nigeria using Owerri, Imo State, as source of data and this is with a view to ascertaining whether the concepts of process quality control are applied in the production of those blocks.

\section{Literature Survey}

Experts have defined quality as all of the features and characteristics of a product or service that contributes to the satisfaction of a customer's needs. These needs involve price, safety, availability, maintainability, reliability and usability. ${ }^{3}$

Quality cannot be inspected into a product; it must be build into it. Also reliability cannot be built into a product, it must be designed into it. So it could be understood that reliability is a consequence of quality which is concerned with satisfaction during use and also the extent to which the product satisfies the purpose ${ }^{4}$.

Quality control is a name given to the collection of management techniques and device used to manage, monitor and control all the steps in the production of a product of desired quality. ${ }^{5}$

Quality control is also described as the act of monitoring specific project results to determine if they comply with relevant standards and identifying ways of eliminating unsatisfactory results. Quality control involves the inspection of products to ensure that product is in line with quality standards sets and also that work is being performed correctly. It also eliminates the need for corrective rework thereby reducing waste of project resources.

\section{Objectives Of Quality Control}

The objectives of quality control is not to eliminate all variability of the items produced which would be an impossible task, but to constrain this variability to economically feasible limits. This include the following:

- To take necessary steps to keep the quality of the product from dropping below the desired level during manufacture.

- To avoid as far as reasonable possible, having product which are of low quality than that which is considered acceptable to reach the customer.

- To set up standard of quality that are readily acceptable to the customer and economical to achieve and maintain.

- To analyze the trend and extent of quality deviation in a part or product during manufacturing and to determine the cause of such deviation by statistical techniques when it cannot be reasonably attributed to chance.

\section{MASONRY}

Masonry is the building of structures from individual units laid in and bound together by mortar. The term masonry can also refer to the units themselves. The common materials of masonry construction are brick, stone such as marble, granite, travertine, limestone, concrete block, glass block, stucco and tile. Masonry is generally a highly durable form of construction. However, the materials used, the quality of mortar and workmanship and the pattern in which the units are assembled can significantly affect the durability of the over all masonry construction ${ }^{5}$.

Masonry is commonly used for the walls of building, retaining walls and monuments. Concrete blocks are the most common types of masonry in use in Imo State and may be either bearing or a veneer concrete blocks especially those with hollow cores offer various possibilities in masonry construction. They generally provide great compressive strength, and are best suited to structures with height transverse loading when the core remain unfilled. Filling some or all of the cores with concrete or concrete with steel reinforcement (typically rebar) offers much greater tensile and lateral strength to structures. 


\section{TYPES OF TECHNIQUES AVAILABLE IN INSPECTION}

There are three type of testing for quality control processes in some of these selected block industries

- Process inspection

- Sampling or lot by lot inspection

- Screening or $100 \%$ inspection

\section{PROCESS INSPECTION}

In this process inspection every stage or process that would be passed through must be inspected from watering (curing) process, handling and storing processes to the time of delivery. This is how some of these industries carry out their process inspection.

\section{SAMPLING OR LOT BY LOT INSPECTION}

This is a kind of statistical method of inspection. It is a visible process where a representative sample is drawn from a lot size of production lot in order to access the acceptability of the whole lot. The numbers of defects are compared with appropriate acceptability quality level (AQL) drawn from sampling plans.

In practice, an $\mathrm{AQL}$ percentage for acceptance number and rejection number depends on the classification of defects such as critical major and minor defects, where quality level percentage for rejection or acceptance depends on the type of defect.

\section{SCREENING OR 100\% INSPECTION}

This technique involves the examination of all component one by one. It is a visible test used in these selected block industries to sort at defective used ones from the production line. Screening is used on the production line and during re-inspection. Inspection of finished production on a screening basis is a technique with proper control which theoretically should be one of the surest way to eliminate defective products from being shipped out. ${ }^{5}$

\section{FACTORS INFLUENCING THE QUALITY OF VIBRATED MASONRY BLOCKS}

The usual factors affecting the strength of concrete under concrete technology include

- Type of cement

- Degree of compaction

- Curing method

- Quality of the aggregates.

\section{TYPES OF CEMENT}

The Dangote Portland cement is by far the biggest player in Nigeria cement production but several other major entities dominate their respective regions. Such types of cement include Ibeto cement, UNICEM, CCNN, Burdhan cement etc. Using Ibeto cement as the reference point, other types of ordinary Portland cement that occasionally find their application in our construction industry could be compared. Ibeto cement has a high percentage of tricalcium silicate $\mathrm{C} 3 \mathrm{~S}$, which allows it to set relatively fast, especially under hot humid conditions of the south. With the same experimental conditions (for example sand cement ratio, quality of water, water cement ratio, others) the setting time and subsequent gain in strength and the ultimate strength of the product of these different type of cement were observed to differ.

CCNN cement will set very slowly but acquires a higher $28^{\text {th }}$ day strength. Burham cement sets with about the same speed as Ibeto cement and acquires also higher $28^{\text {th }}$ days strength. UNICEM sets relatively slower than Ibeto and has almost the same ultimate $28^{\text {th }}$ day strength. ${ }^{5}$ The knowledge of the performance of these different types of cement places one on a better position to make appropriate choice especially during unfavorable rain season conditions for improved efficiency.

\section{COMPACTION}

Compaction ensures better bonding between the aggregates. The bonding to a greater extent determines how strong or weak the product will be. During masonry blocks manufacturing, the vibration which ensures the compaction is closely linked with the manner of placing the sand mix into the mould and the subsequent drying down of the rammer against the mix in the mould. Observations under this will be treated under latent factor methods of placing mix into the mould.

\section{CURING}

Curing ensures the appropriate medium for hydration of the cement clinkers, which is the major physicochemical reaction that produces setting and hardening of masonry blocks. Curing mechanism and program is a major determinant of strength of masonry blocks. 


\section{QUALITY OF AGGREGATES}

The aggregates for the manufacture of masonry blocks are sand. The ability of the cement (binder) to hold and hold firmly the aggregates together determines also the degree of the ultimate strength of the products. Sand of different geological formations will not only differ in strength but also in the yield, aesthetic and other qualities of he products.

\section{LATENT FACTORS AFFECTING THE STRENGTH OF MASONRY BLOCKS}

During masonry blocks manufacturing certain factors not easily noticeable and which are often ignored affect the immediate and ultimate strength of the product. After several months of experimental observations and under controlled conditions, the following factors are observed to affect the overall strength of masonry blocks.

- Type, quality and grade of aggregates

- Quality of mix

- Time lag between mixing and placing of mix into mould

- mode of placing mix into mould before compaction

- Curing mechanism/regime

- Measures under unfavourable weather condition.

\section{TYPE QUALITY AND GRADE OF AGGREGATES (SAND)}

The properties of the aggregate that affect the strength of masonry blocks include among others cleanliness, size and the sharpness of the aggregate. Dirty and unclean aggregates will result in side reactions with the cement. The acidic and other chemical contents of the dirty aggregate will retard the gain in strength through the release by products of either soluble or amorphous substances which greatly influenced the strength. Aggregates for masonry blocks must be very clean and most often from deep river water. White river sand, washed and pumped by machines are recommended. ${ }^{5}$ The size of the aggregate must as much as possible lie within the limits of the grade of aggregates called sand i.e. within $0.2-0.3 \mathrm{~mm}$ in diameter. On no account will silt be used. The use of silt has the disadvantage of low yield and low ultimate strength of the masonry block. Again the larger the aggregates the more the yield and the stronger the masonry blocks. Very sharp edged aggregates provide easy and favourable bonding surface for the cement clinker and the aggregates. When aggregates are not sharp or are coated with thin films of dust the bonding is restricted and this results in reduced ultimate strength of the masonry block.

\section{QUALITY OF MIX AND MIXING METHOD}

These factors seem among others to have major influence on the ultimate performance every sand grain since it must be properly mixed to come in contact with the cement clinker to ensure proper bonding. To achieve this the cement is placed on the measured quality of sharp sand and a fresh mould built up with each of the 5-6 cycles of mixing. In doing so shovel/spade scooping are placed at the apex of the mound and on rolling sown the mound, cement and sand are properly mixed together. When the mix is ready for placing into the mould it maintains a homogeneous colour and texture all through without a trace of the colour of cement or sand. The quality of water added is also determined by the colour of cement or sand. The quantity of water added is determined by the wetness or otherwise of the sand and also by the weather conditions. During dry hot (harmattan) conditions a little excess water is added to reduce dry shrinkages during setting and hardening before curing starts. Again the quantity of water added must be related to the conditions of workability. Water used must be fit for drinking.

\section{TIME LAG BETWEEN MIXING AND MOULDING}

This is the most essential in determining the ultimate strength. Hydration of cement clink which is the major physicochemical process of setting and hardening of concrete starts immediately the water gets in contact with the cement clinkers. To achieve optimal strength of each masonry blocks, the mixing must be fast and therefore immediately followed by moulding. Delay in moulding after the fresh cement-sand-water mix is rarely a source of weakness in the blocks. The implication of this is that the aggregate component is increased with very low cement sand ratio. The ultimate result is a very weak product, which after the $28^{\text {th }}$-day period remains brittle and fragile.

\section{PLACING AND REFILLING OF MOULD WITH MIX}

This salient factor could be responsible for reduced strength of masonry blocks if it is not properly checked. When mix is placed on the mould and the vibration of each mould initiated, care must be taken to ensure that the vibration mould overflows with the mix before the rammer is driven down into the mould. In this circumstance, it is recommended to use the "protector" to remove the excess mix on the mould rather than using 
the spade or by hand. Although this will prolong the "mature" period of the vibration but it ensures that enough quality of the mix is compacted together to reduce the existence of honey-combs and ensure greater strength.

\section{DURATION AND DEGREE OF COMPACTION}

In concrete technology, degree of compaction is one of the major determinants of strength of the concrete product, hence the need for the opportunities of this very factor. Maturity period of vibration of masonry blocks is reached when the rammer vibrates freely within the mould. When this happens the vibrator is switched off and the mould is lifted up the fresh block with clear and distinct lifter -strikes, correctly made to avoid devibration of the fresh compacted block.

\section{MEASURES UNDER UNFAVOURABLE WEATHER CONDITIONS}

During harmattan periods the fresh moulds lose water very easily to the surrounding air and more often than not, this results in drying shrinkages. There is need to guard against this effect. Fresh molds must be attended to and measures taken to ensure that they are constantly humid/we at least for 3 days from the day of molding. The easiest way to achieve this, especially during massive production of blocks is to constantly spray water on the masonry blocks as against covering them with wet sacks. Also during rainy season, it is common occurrence to experience rainfall while molding just there after before the placed fresh masonry blocks from melting down by the rain, light cellophane sheets are used to cover the blocks. For easy handling, the blocks are arranged in rows of 10-15 blocks. Corridors are created after very 4 rows to create spaces for unduly long periods, the strength of the blocks are reduced. Hence the sheets are to be removed immediately the threats posed by the rain are over. Again the removal of the sheets must be guarded so as not to deface the blocks. In this regard the sheets are lifted up from the blocks rather than pulling or rolling them on the blocks.

During wet seasons the white sharp river sand is Saturday with moisture/water. The yield (that is the number of block per given quantity of sand) is increased. In order to maintain the same sand block ratio the quantity of sand ordinarily required for a bag of cement (sand cement ratio) must be lowered for maximum strength.

\section{Methodology}

40 copies of the questionnaire for this research work was distributed to the staff and management of selected block industries in Owerri Municipality. 35 copies that were duly completed were used for the analysis. The respondents include managers, machine operators, block carriers, and admin. staff. The research employed the following sources for both primary and secondary data collection: questionnaire, personal interview, journals, libraries and internet. The primary data was sourced from the randomly selected six block industries that include the following:

- Maximum Block Industry,

- Tony White Block Industry,

- Uzokwe Block Industry,

- Solid Base Block Industry,

- G.O.D Block Industry, and

- Top Choice Block Industry, all in Owerri Imo State.

\section{Results And Discussion}

When the respondents were asked to say the reason for low quality blocks, $90 \%$ of them strongly agreed that poor quality of input materials was the cause. Also $85 \%$ of them agreed that the production machines are also responsible. In a separate question ask the respondents concerning the contribution of machine operators and the packaging and storing activities in producing low quality blocks, $57 \%$ and $85 \%$ agreed in the affirmative respectively.

When the respondents were asked to assess the knowledge of quality control principles and concepts and their application in the production of masonry blocks, by owners and managers of the block industries, $85 \%$ of the respondents believe those companies do not know about process quality control concepts and its application.

From the analysis of the collected data, it was seen also that the block industries who are mechanized are the ones that fully apply process quality control concepts, and they are very few; while those that are not mechanized do not know about the concepts nor its application in their production processes; and they are in the majority.

Analysis of the research data revealed also that there is no significant relationship between educational qualification and workers performance in those small and medium scale block industries. Data analysis also further disclosed that generally speaking, process quality control concepts are not applied in the production of 
masonry blocks in majority of the small and medium scale block industries, even though data from those interviewed showed that customers get their supplies mainly from these groups.

\section{Conclusions}

Based on the research problem, the analysis of results and discussion, this study made the following conclusions. Masonry block industries do not have competent process quality control managers, who should supervise and direct the activities involved in block production.

The managers are not able to understand the pre-process quality control measures which required them to monitor or control all the materials for masonry blocks. Also, the management and control of materials entering the process is not given necessary attention, that should ensure that the finished product at the end would conform to the industry's and customer's specifications and quality standard.

The managers also do not have the knowledge of in-process quality control measurement which is based on a measure of the controlled quality characteristic as the product is generated. This should teach them how to initiate signals to regulate or stop the process to prevent substandard production of masonry blocks on time.

It is observed that the reason for collapse of finished building or buildings in construction projects is as a result of poor quality masonry blocks used in project delivery block work; if were thorough process quality control is applied in the production of these blocks right from the beginning, this problem would not occur, and project delay or abandonment would also not happen.

\section{Recommendations}

Based on the conclusions of this study, this paper recommends as follows, since masonry blocks are very important materials for construction projects activities especially buildings, in Nigeria:

- Managers should carefully supervise or inspect the workers especially during the process of mixing aggregates to get the cement-sand-water ratio right in order to ensure that every grain of sand is properly mixed together with cement, so as to ensure proper bonding for maximum product performance.

- Modern machines and equipment should be made affordable for efficiency and for testing of the masonry blocks. For instance a 4 and 10 layers machine should be secured by these firms and a crushing machine for checking the compressive strength of blocks also acquired.

- Conferences and seminars should be organised for the directors, managers and workers of block industries so that they will be aware of current performances, especially with regard to the application of process quality control techniques.

- Since masonry blocks are the fundamental material in building construction projects, more attention by the governments should be paid to the materials used for it's production in order to ensure maximum strength and performance.

With these contributions, the building construction project industry will go a long way to addressing the problem of building and infrastructural collapse in our country.

\section{References}

[1]. Bester, N. (2007) Construction Project Management Planning and Scheduling. Delmar Publishers, New York

[2]. Ucy, T. (2005): Quality techniques, An Instruction Manual; $3^{\text {rd }}$ ed. London D.P Publishers Ltd.

[3]. Dale, B.G and Plunket, J.J (2008): Managing Quality; Philip Alan Publishers, London.

[4]. Armand, H. (2006): Elements of Project Management plan, Schedule and Control. New Jersey press, Englewood Cliff

[5]. Okereke, P.A. (2003): Construction Materials, Testing and Quality in Tropical Climate. Crown Publishers Ltd. Owerri.

[6]. Feignbaum, A.V. (2008) Total Quality Control $3^{\text {rd }}$ ed. Mc Graw-Hill, New York.

[7]. Bertrand, L.H and Prayhakar M.G. (2005): Quality Control and Application, Prentice Hall International Inc. Englewood Cliffs, N.J.

[8]. Vorobiev V.A. and Komar A.G. (2005) building Materials. Moscow. Stroizdat. 